\title{
RA?EGA
}

O ESPACYO GEOGRÁFICO EM ANÁLISE

\section{ASPECTOS HIDROLÓGICOS E HIDROGEOLÓGICOS DA BACIA DO RIO FERVIDA, AQUÍFERO CARSTE, COLOMBO, PARANÁ.}

\section{HYDROLOGICAL AND HYDROGEOLOGICAL ASPECTS OF FERVIDA WATERSHED, KARST AQUIFER, COLOMBO, PARANÁ.}

\author{
Luiz Eduardo Mantovani \\ Universidade Federal do Paraná \\ Curitiba, PR, Brasil \\ e-mail: lem@ufpr.br \\ Elenice Fritzsons \\ Embrapa Florestas \\ Colombo, PR, Brasil \\ e-mail: elenice.fritzsons@embrapa.br \\ Marcos Silveira Wrege \\ Embrapa Florestas \\ Colombo, PR, Brasil \\ e-mail:marcos.wrege@embrapa.br
}

Recebido em: 27/05/2015

Aceito em: 25/07/2016

\section{Resumo}

A segurança das áreas metropolitanas quanto ao abastecimento de água é um grande desafio para os próximos anos, especialmente no Brasil, devido ao crescimento descontrolado dos grandes centros urbanos, a expansão das áreas de mananciais e poluição. A bacia de Fervida, sub-bacia de Ribeirão da Onça, faz parte do Aquífero Carste presente na Região Metropolitana de Curitiba, Paraná. Nessa bacia há extração de água subterrânea e uma elevada demanda de água para a produção de hortaliças. Portanto, o objetivo desse estudo foi dimensionar a evapotranspiração e também o escoamento superficial, confrontando os dados obtidos nesse trabalho com os dados de pesquisa já efetuados e, dessa forma, colaborar para a compreensão do balanço hídrico dessa região. Para isso, foram analisados dados de vazão e precipitação entre 1998 e 2003, quando havia também monitoramento de vazão no exutório da bacia. Os resultados obtidos mostram que a pluviosidade média anual na bacia, para o período proposto no trabalho, foi de $1609 \mathrm{~mm} / \mathrm{a}$ e a média anual de evaporação foi de, aproximadamente, $892 \mathrm{~mm} / \mathrm{a}$. 
Considerando o escoamento superficial e a extração de água por meio dos poços, verificou-se que o balanço hídrico da bacia foi negativo em $395 \mathrm{~mm} / \mathrm{a}$. Isso sugere que há entrada de fluxos subterrâneos, corroborando com resultados obtidos em outros trabalhos.

Palavras-chave: segurança hídrica; balanço hídrico; escoamento superficial

\begin{abstract}
The water supply and water security of metropolitan areas is a major challenge for the coming years, especially in Brazil, due to the uncontrolled growth of large urban centers, expansion of the watershed areas and polluting activities of water. The Fervida watershed is part of karst area located at the metropolitan region of Curitiba, Paraná. In it there is groundwater extraction and strong water consumption for vegetables production. The aim of this study was to scale the evapotranspiration and also the runoff, comparing the data obtained in this work with researches data already obtained by others authors and thus, to contribute for understanding of water balance of the region. To this objective, flow and precipitation data were analyzed between 1998 and 2003, because in this time there was also flow monitoring in the mouth of the basin. The results show that the average annual rainfall in the basin between 1998 and 2003 was 1609 $\mathrm{mm} / \mathrm{a}$ and average annual evaporation of $892 \mathrm{~mm} / \mathrm{a}$. Considering the water runoff of water and water extraction through the wells, it was found that the water balance of the basin was negative $(-395 \mathrm{~mm} / \mathrm{a})$, which suggests that there is incoming groundwater flow, which confirms results obtained in other works.
\end{abstract}

Key words: water security; water balance; runoff

\title{
1. INTRODUÇÃO
}

O abastecimento de água nas regiões metropolitanas dos grandes centros urbanos constitui um grande desafio para os próximos anos devido ao aumento na demanda por água potável. Isso ocorre não somente pelo crescimento da população e inchamento das cidades, mas também devido ao avanço da urbanização para as áreas vizinhas e áreas de recarga dos mananciais. Dessa forma, a expansão das áreas urbanas tornou-se um problema mais grave do que o crescimento demográfico em si (BOLLIMAN et al. 2013). Além disso, a segurança hídrica, implícita ao conceito de desenvolvimento sustentável, constitui um novo desafio, amplamente divulgado pelas organizações voltadas para as questões ambientais, pois estende 0 conceito de disponibilidade não somente às pessoas, mas também aos ecossistemas. 
O Aquífero Carste situa-se na RMC (Região Metropolitana de Curitiba) e representa um potencial de exploração econômica segura para 0 abastecimento dessa região, com menores custos de exploração, adução e tratamento, se comparadas às alternativas de captação nos mananciais superficiais dos rios Várzea e Açungui (BOLLIMAN et al., 2013), sendo uma alternativa para complementar o abastecimento, com qualidade, por meio de suas fontes naturais (HINDI et al., 2013).

As regiões cársticas representam 7 a $12 \%$ da área continental e aproximadamente um quarto da população mundial é completamente ou parcialmente dependente destas águas para abastecimento. Estes aquíferos podem ser seriamente impactados por mudanças climáticas futuras que envolvem redução de precipitação e elevação de temperatura (HARTMAN et al, 2014), ou seja, devido a alteração no balanço hídrico.

O aquífero Carste da RMC faz parte de uma área maior de abrangência das rochas carbonatadas no estado do Paraná, que não ocorre apenas nesse local, mas em aproximadamente $5.570 \mathrm{~km}^{2}$ (2,8\% do Estado) e, na RMC, estas rochas distribuem-se especificamente nos municípios de Almirante Tamandaré, Colombo, Campina Grande do Sul e Rio Branco do Sul, na bacia do Ribeira e, também, em Araucária e Curitiba, na bacia do Iguaçu (ROSA FILHO et al., 2011).

Devido à carstificação das rochas carbonáticas (metadolomitos) há armazenamento de água subterrânea que adquire natureza alcalino-terrosa cálcio-magnesiana, o que torna a bacia adequada para produção de água para consumo agrícola e abastecimento da população.

A bacia do rio Fervida, sub-bacia de Ribeirão da Onça, faz parte do aquífero cárstico e situa-se em Colombo, na RMC. Devido ao uso intenso de irrigação por aspersão, vários estudos foram efetuados para dimensionar o ciclo hidrológico da bacia, incluindo escoamento médio, balanço hídrico e evapotranspiração (LISBOA e BONACIM, 1995; PROJETO KARST, 1998; VESTENA e KOBYAMA, 2007). Estes estudos são fundamentais, devido à importância estratégica da bacia que conjuga o uso intensivo de cultura agrícola irrigada com explotação de água subterrânea, tanto para o presente, 
quanto para ser referenciado em cenários futuros, devido às mudanças climáticas.

No inicio da exploração deste aquífero houve sérios problemas, tais como subsidências e colapsos de terreno, com graves avarias em várias residências; secamento ou redução de vazão de fontes naturais e de rios e com prejuízo para o abastecimento doméstico, agricultura e criação de animais (HINDI et al., 2002).

Portanto, o objetivo deste estudo foi dimensionar a evapotranspiração e também o escoamento superficial e o balanço hídrico da bacia do rio Fervida e comparar os dados obtidos nesse trabalho com os dados de pesquisas já efetuadas para essa bacia.

\section{MATERIAL E MÉTODOS}

A bacia de Fervida está localizada a noroeste do município de Colombo, entre as coordenadas geográficas $25^{\circ} 15^{\prime} 00^{\prime \prime}$ e $25^{\circ} 17^{\prime} 30^{\prime \prime}$ de latitude Sul (S) e 4909'00" e 49¹3'00" de longitude oeste (W) (entre 680.000 e 688.000 e 7206000 e 7202000 coordenadas UTM), compondo 16,68 km² de área (Fig. 1). Segundo a classificação de Köeppen, baseada na temperatura e pluviosidade, o tipo climático da região é $\mathrm{Cfb}$, que se define como sendo clima pluvial temperado, mês mais frio com temperaturas situadas entre -3 e $18{ }^{\circ} \mathrm{C}$. A precipitação é regular ao longo do ano e, geralmente, não há estação seca definida, podendo ocorrer geadas severas, raramente nevadas (MAACK, 1981). 

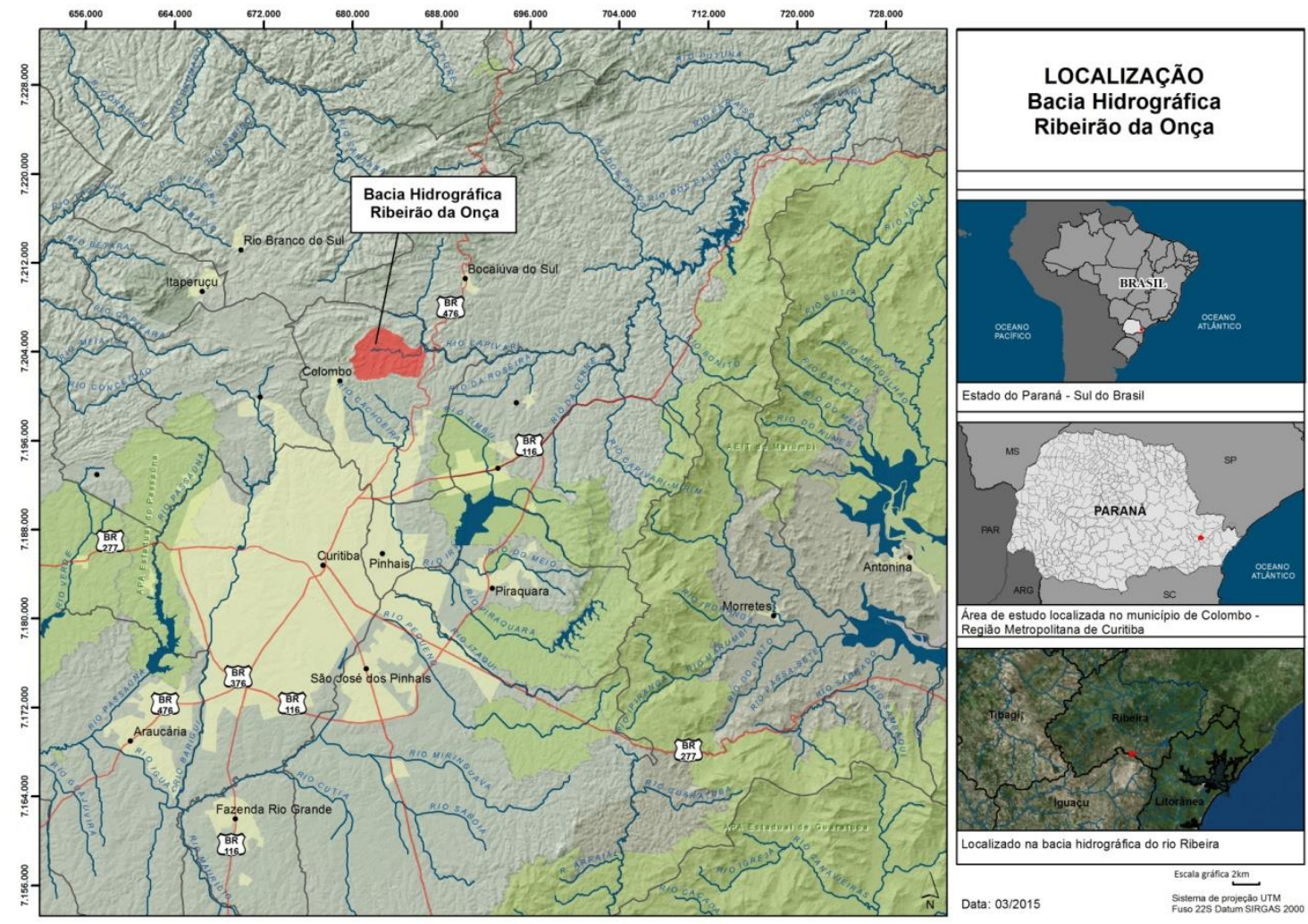

Figura 1. Localização da bacia hidrográfica do rio Fervida (sub-bacia de Ribeirão da Onça)

A área de estudo está localizada no denominado Primeiro Planalto Paranaense, nos domínios de rochas do Grupo Açungui. O Grupo Açungui foi subdividido originalmente por Bigarella e Salamuni (1958) nas formações Setuva, Capiru e Votuverava, considerando da base para o topo. A primeira situada na base do Grupo Açungui, aflora em uma estreita faixa, em torno da Anticlinal do Setuva ao norte de Bocaiúva do Sul, e no Núcleo Betara, a leste de Rio Branco do Sul. Enquanto a Formação Votuverava, aflora a noroeste de Rio Branco do Sul. Já a Formação Capiru se encontra ao sul e separada das demais pela Falha da Lancinha. Essa última formação, juntamente com a Formação Turvo-Cajati de idade Toniano ao Ediacarano e o Complexo Atuba (Arqueano a Paleoproterozoico) todas formam o Terreno Curitiba (FALEIROS et al., 2011). A Formação Capiru datada no Neoproterozóico é composta por faixas alongadas em vários quilômetros e de larguras hectamétricas de filitos, metadolomitos e quartzitos.

A bacia hidrográfica do rio Fervida é uma sub-bacia do Ribeirão das Onças que, por sua vez, faz parte da bacia do rio Capivari que compõe a bacia 
do rio Ribeira de Iguape. A bacia do Rio Fervida apresenta altitudes que variam de $1060 \mathrm{~m}$ nas nascentes a $920 \mathrm{~m}$ em seu exutório. A densidade de drenagem vai de média a forte, com padrão de drenagem assimétrico e com presença de dolinas e uvalas. A orientação de escoamento principal do rio Fervida é no sentido de oeste para leste (FRITZSONS et al. 2010).

O uso predominante da área é de pequenas propriedades produtoras de hortaliças, sendo que o uso e cobertura da terra apresentam os seguintes valores: 9,39\% são edificações, 38,81\% são florestas, 20,52\% de silvicultura, $29,73 \%$ de agricultura, $1,73 \%$ de pastagem e $1,17 \%$ de mineração (FRITZSONS et al. 2015). Há um uso intensivo da irrigação para a cultura de hortaliças.

A bacia foi delimitada e os dados de vazão foram cedidos pelo Instituto das Águas do Paraná, obtidos a partir de um monitoramento de vazão situado a $4 \mathrm{~km}$ a montante do exutório da bacia do rio Fervida (Código Aneel - Agência Nacional de Energia Elétrica - 81290500; localização: latitude 2516163" S e longitude 4910'11" W). As observações das cotas de vazão no rio Fervida tiveram início em 07/07/97 e finalizaram em 2003.

A precipitação para o mesmo período foi obtida no Sistema de Informações Hidrológicas - SIH do AGUASPARANÁ (Instituto das Águas do Paraná, 2015), sendo a estação de Colombo, monitorada pela Copel, código 2549090 (latitude 2517'15” S e longitude 49¹3’50” W).

As equações utilizadas no trabalho são descritas em seguida. Coeficiente de escoamento superficial (C), ou coeficiente runoff, ou ainda coeficiente de deflúvio é definido como a razão entre o volume de água escoado superficialmente e o volume de água precipitado. Este coeficiente pode ser relativo a uma chuva isolada ou relativo a um intervalo de tempo onde várias chuvas ocorreram. Obteve-se o volume (V) de água precipitado na bacia da seguinte forma:

$$
\mathrm{V}\left(\mathrm{m}^{3}\right)=\mathrm{A}\left(\mathrm{km}^{2}\right) \times 10^{6} \times \mathrm{P}(\mathrm{mm}) \times 10^{-3} \quad \text { Eq. } 1
$$

Em que: $A$ é a área da bacia $\mathrm{em}^{\mathrm{km}} \mathrm{k}^{2}$ e $\mathrm{P}$, a precipitação, em $\mathrm{mm}$, multiplicada por $10^{-3}$ para a transformação em $\mathrm{m}^{3}$. 
Na sequência, a vazão total anual $(\mathrm{Qa})$, em $\mathrm{m}^{3}$, foi obtida pela seguinte expressão:

Qa $\left(\mathrm{m}^{3}\right)=\mathrm{Qm}$ anual $\left(\mathrm{m}^{3} \mathrm{~s}^{-1}\right) \times 365 \times 24 \times 3600$

Eq. 2

Onde a Qm (vazão média anual) foi obtida pela observação das cotas de vazão, multiplicada pelo número de dias em um ano, horas de um dia e segundos de uma hora.

Assim, o escoamento médio anual ou coeficiente de escoamento - C (em \%), pode ser obtido por meio de uma regra de três simples.

$$
\mathrm{C}=\mathrm{Qa} \times 100 / \mathrm{V}
$$

Em que: Qa é a vazão total anual e V o volume precipitado durante um ano na bacia.

A vazão específica constitui uma estimativa de indicador regional (TUCCI, 2002). A vazão mínima específica é dada por:

$$
q=Q \min / A
$$

Eq. 4

Em que: $Q$ min é a menor vazão do período estudado em $L / s$, e $A$ é a área da bacia em $\mathrm{km}^{2}$. Para a vazão média, na equação 4 , troca-se a vazão mínima (Qmin) por Qm ( vazão média).

Para o cálculo da evapotranspiração, foram utilizados os dados de temperatura média a partir de Wrege et al (2011) provenientes da Estação: 25254905 - Pinhais (Simepar), que é a estação meteorológica mais próxima da área de estudo distando, aproximadamente, $20 \mathrm{~km}$. Os valores de evapotranspiração potencial de Thornthwaite foram calculados usando as seguintes expressões:

$$
E T P=f \times 16 \times(10 \times \text { tmed/l })^{a}
$$

\section{Em que,}




$$
\begin{array}{ll}
f=[0,006 \times(-1) \times \text { latitude }+1,01] & \text { Eq. } 6 \\
I=\sum_{\mathbf{1 2}}^{\mathbf{1}}(\mathbf{t m e d} / \mathbf{5})^{\mathbf{1}, \mathbf{5 1 4}} & \text { Eq. } 7 \\
\mathrm{a}=6,75 \times 10^{-7} \times \mathrm{I}^{3}-7,71 \times 10^{-5} \times \mathrm{I}^{2}+0,01791 \times \mathrm{I}+0,492 & \text { Eq. } 8 \\
\text { Em que: } &
\end{array}
$$

ETP: evapotranspiração potencial $(\mathrm{mm})$

f: representa a função de ajuste do modelo para cada local, considerando-se que a equação é dada para calcular a ETP em um período de 12 horas de brilho solar, o que não ocorre em todas as regiões;

I: é o índice anual de calor;

a: é a função cúbica do índice anual de calor;

t med: é a temperatura média do ar nos meses de janeiro a dezembro, em ${ }^{\circ} \mathrm{C}$;

$\sum_{12}^{1}$ tmed: é o somatório das temperaturas médias do ar de janeiro a dezembro, em ${ }^{\circ} \mathrm{C}$.

A coordenada latitude, na equação, foi expressa em graus decimais e valores negativos, servindo para calibrar os valores de ETP do local. A série da temperatura utilizada para fazer os cálculos foi a mesma da precipitação (1998 a 2003).

$\mathrm{Na}$ equação de balanço hídrico ficam evidentes as variáveis hidrológicas mais importantes: precipitação, evapotranspiração, deflúvio e armazenamento superficial e subterrâneo. A quantidade de água em cada fase do ciclo pode ser avaliada por esta equação (Lei da Conservação da Massa), sendo (BARTH, 1987):

$$
\mathrm{P}-\mathrm{ET}=\mathrm{C}+\Delta \mathrm{S}
$$

Onde: $\mathrm{P}=$ precipitação; $\mathrm{ET}=$ evapotranspiração, $\mathrm{C}=$ deflúvio (escoamento) e $\Delta S$ = variação no armazenamento no tempo.

\section{RESULTADOS E DISCUSSÃO}

Aplicando as equações para o escoamento da bacia, verificou-se que para o ano de 1998, por exemplo, o volume precipitado anual (V) em toda a 
bacia hidrográfica foi $1893 \mathrm{~mm}$ ou $31.575 .240 \mathrm{~m}^{3}$. A vazão média $(\mathrm{Qm})$ desse ano, obtida no exutório da bacia hidrográfica foi de $0,41 \mathrm{~m}^{3} \mathrm{~s}^{-1}$, o que resulta na vazão anual $(\mathrm{Qa})$ de $12.929 .760 \mathrm{~m}^{3}$ e o escoamento médio anual $(\mathrm{C})$ de $41 \%$. Este mesmo cálculo foi feito para os anos de 1998 a 2003 (Tabela 1).

Tabela 1. Porcentagem média de escoamento direto/precipitação, de "perda" e vazão específica para os anos de 1998 a 2003.

\begin{tabular}{cccccccc}
\hline 1 & 2 & 3 & 4 & 5 & 6 & 7 & 8 \\
\hline 1998 & 1893 & 0,41 & 41 & 776,13 & 59 & 1116,87 & 24,6 \\
1999 & 1574 & 0,37 & 44 & 692,56 & 56 & 881,44 & 22,2 \\
2000 & 1300 & 0,34 & 49 & 637,00 & 51 & 663,00 & 20,4 \\
2001 & 1865 & 0,45 & 45 & 839,25 & 55 & 1025,75 & 26,9 \\
2002 & 1474 & 0,42 & 53 & 781,22 & 47 & 692,78 & 25,2 \\
2003 & 1553 & 0,37 & 45 & 698,85 & 55 & 854,15 & 25,2 \\
*Média & $\mathbf{1 6 0 9}$ & $\mathbf{0 , 3 9}$ & $\mathbf{4 6 , 2}$ & $\mathbf{7 4 3 , 3 6}$ & $\mathbf{5 3 , 8}$ & $\mathbf{8 6 5 , 6 4}$ & $\mathbf{2 3 , 6}$ \\
\hline
\end{tabular}

NOTA: * média resultante dos seis anos.

Ref: 1. Ano; 2. Precipitação total anual $(\mathrm{mm})$; 3. Vazão média anual $-\mathrm{Q}\left(\mathrm{m}^{3} \cdot \mathrm{s}^{-1}\right)$; 4. Escoamento direto médio (\%); 5. Escoamento direto médio (em $\mathrm{mm}) ; 6$. Evapotranspiração média anual somada à infiltração (\%); 7. Evapotranspiração média anual e infiltração (em $\mathrm{mm}$ ) e 8. Vazão específica $\left(\mathrm{Ls}^{-1} \mathrm{~km}^{-2}\right)$.

Assim, o escoamento médio anual para os seis anos esteve entre 41 a $53 \%$ do volume total precipitado na bacia (coluna 4, Tabela 1).

Considerando que a média anual da precipitação para esses seis anos foi de $1609 \mathrm{~mm}$, os $46,2 \%$ (ou $743,36 \mathrm{~mm}$ ) representam o escoamento superficial da bacia. Isso significa que as "perdas" referentes à infiltração e evapotranspiração são de 866 mm/ano (743,36mm subtraído de 1609 mm), o que representa $53,8 \%$ do total precipitado. Assim, os valores médios encontrados para os seis anos estiveram entre 41 e $53 \%$ de escoamento direto/precipitação e o percentual de "perda" (evapotranspiração e infiltração)

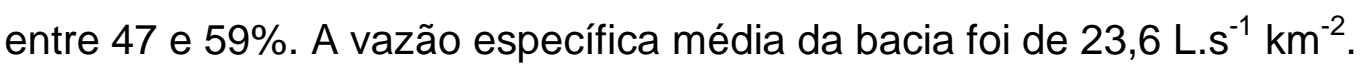

Quanto a evapotranspiração média anual, calculada para esse trabalho no período selecionado, foi de $892,37 \mathrm{~mm}$ (Tabela 2). Esse valor é muito próximo ao encontrado com base no cálculo para as "perdas" do escoamento médio anual superficial, com uma diferença de apenas $26,37 \mathrm{~mm}(865,6 \mathrm{~mm} / \mathrm{a}$, 
da coluna 7, Tabela 1, subtraído de 892,37 mm/a, evapotranspiração média, Tabela 2).

Tabela 2. Evapotranspiração potencial calculada pelo método de Thornthwaite para a bacia de Fervida

\begin{tabular}{c|r|r|r|l|l|l|l|l|l|l|l|l|l}
\hline MESES / ANO & jan & fev & mar & abr & mai & jun & jul & ago & set & out & nov & dez & ANO \\
\hline 1998 & 99,54 & 102,05 & 100,37 & 72,26 & 51,17 & 43,22 & 48,66 & 60,32 & 57,65 & 65,83 & 76,68 & 95,43 & 873,19 \\
\hline 1999 & 100,58 & 103,05 & 101,40 & 73,54 & 52,47 & 44,49 & 48,72 & 53,74 & 63,68 & 58,30 & 67,83 & 92,51 & 860,30 \\
\hline 2000 & 96,91 & 96,09 & 86,45 & 78,75 & 54,82 & 60,81 & 33,50 & 50,97 & 54,17 & 85,67 & 81,03 & 96,09 & 875,25 \\
\hline 2001 & 105,37 & 107,16 & 103,59 & 88,20 & 51,36 & 48,17 & 49,43 & 58,70 & 58,02 & 69,42 & 84,12 & 89,03 & 912,57 \\
\hline 2002 & 96,80 & 89,87 & 109,49 & 91,58 & 65,30 & 60,25 & 41,38 & 63,11 & 50,08 & 87,33 & 84,83 & 94,17 & 934,21 \\
\hline 2003 & 101,03 & 116,14 & 94,24 & 80,50 & 52,59 & 61,33 & 52,59 & 42,66 & 57,90 & 69,90 & 80,50 & 89,29 & 898,67 \\
\hline Média geral & 100,04 & 102,39 & 99,26 & 80,81 & 54,62 & 53,04 & 45,72 & 54,92 & 56,92 & 72,74 & 79,17 & 92,75 & 892,37 \\
\hline
\end{tabular}

Pode-se verificar (Tabela 2) que os maiores valores de evapotranspiração se concentram no verão e os menores valores, no inverno e que o acumulado no ano é inferior ao volume precipitado, indicando um saldo positivo no balanço hídrico. Este excedente de água pode ficar armazenado e sofrer escoamento superficial, principalmente no verão. Existe, ainda, uma variabilidade entre os anos, com diferença de $61,12 \mathrm{~mm}$ entre o ano de maior precipitação (2002) e o de menor precipitação (1999), o que equivale à evapotranspiração média mensal intermediária entre os meses de setembro e outubro, por exemplo.

No projeto Karst (1998), foram estimadas as médias da evapotranspiração real e da evapotranspiração potencial por vários métodos (Morton, Penman, Thornthwaite-Mather e Turc) utilizando séries históricas da estação meteorológica de Piraquara, pertencente ao Instituto Agronômico do Paraná (IAPAR) no período de 1974 a 1993 (19 anos), portanto anterior ao período avaliado nesse trabalho. Esta série foi seguida pela estação meteorológica situada no município de Pinhais, hoje pertencente ao Sistema Meteorológico do Paraná (código 25254905- SIMEPAR). Outros cálculos foram feitos pela Copel e apresentados pelo Projeto Karst (1998) (Tabela 3).

jan fev mar abr mai jun jul ago set out nov dez Total


ASPECTOS HIDROLÓGICOS E HIDROGEOLÓGICOS DA BACIA DO RIO FERVIDA, AQUÍFERO CARSTE, COLOMBO, PARANÁ.

\begin{tabular}{rrrrrrrrrrrrrr}
\hline A & 132,0 & 117,7 & 108,6 & 72,4 & 51,9 & 38,1 & 37,5 & 53,9 & 76,0 & 104,5 & 118,5 & 129,5 & 1040,6 \\
B & 109,1 & 93,4 & 84,2 & 57,9 & 41,2 & 32,8 & 38,3 & 51,3 & 62,3 & 85,0 & 97,2 & 102,8 & 855,5 \\
C & 97,5 & 87,8 & 83,9 & 61,0 & 46,2 & 36,5 & 36,6 & 43,3 & 48,0 & 65,7 & 77,5 & 91,8 & 775,7 \\
D & 88,2 & 84,8 & 76,5 & 58,4 & 56,6 & 53,4 & 51,1 & 47,4 & 59,2 & 67,1 & 70,6 & 80,5 & 793,8
\end{tabular}

NOTA: A - Evapotranspiração Real (mm) - Método De Morton; B-: Evapotranspiração Potencial $(\mathrm{mm})$ - Método De Penman; C - Evapotranspiração Potencial $(\mathrm{mm})$ - Método De ThornthwaiteMather; D - Evapotranspiração Real (mm) - Método De Turc.

Fonte: Projeto Karst, 1998.

Os cálculos efetuados pelo Projeto Karst (1998) para o período situado entre 1974 e 1993 resultaram em uma evapotranspiração de 54\% do total precipitado, sendo o restante, $46 \%$, referente ao escoamento superficial somado a explotaçâo do aquífero e recarga subterrânea. Esses valores são próximos aos encontrados nesse trabalho, utilizando os dados de 1998 a 2003.

Para a bacia hidrográfica do Alto Capivari, do Alto Ribeira, vizinha à bacia hidrográfica do rio Fervida, Fritzsons e Mantovani (2010) estimaram em $52 \%$ a percentagem média de escoamento e $48 \%$ referente a evapotranspiração e infiltração somados. No restante do Estado, com exceção da bacia litorânea (Ex: rios Nhundiaquara e Marumbi), a taxa de escoamento superficial estimada foi de $42 \%$. Para a bacia hidrográfica do rio Nhundiaquara, foi encontrado um índice de $68,8 \%$ de escoamento superficial (JICA, 1995). Entretanto, essa bacia hidrográfica é bastante diferenciada, pois o escoamento é muito forte, em função do relevo da Serra do Mar e das rochas (granitos e metamórficas de alto grau) mais resistentes e menos permeáveis.

Assim, baseado em JICA (1995), os resultados encontrados nesse trabalho apresentam uma média percentual de escoamento superficial e evapotranspiração potencial próximas à geral do estado do Paraná.

$\mathrm{Na}$ área de estudo, a menor vazão observada entre 1998 a 2003 foi de 0,11 $\mathrm{m}^{3} \mathrm{~s}^{-1} \mathrm{em} 1998$ (INSTITUTO DAS ÁGUAS DO PARANÁ, 2015), após uma semana sem precipitação. Sendo a área da bacia hidrográfica de $16,68 \mathrm{~km}^{2}$, pode-se considerar a vazão mínima específica para o amostrado de $6,6 \mathrm{~L} \mathrm{~s}^{-1}$ $\mathrm{km}^{-2}$ (equação 4). Essa vazão mínima específica apresenta valor próximo do estimado pela agência JICA (1995) para o aquífero cárstico, cuja média de 
vazão mínima específica para um período de estiagem de sete dias, seria de $8,9 \mathrm{~L} \mathrm{~s}^{-1} \mathrm{~km}^{-2}$.

Para a porção superior do Alto da Bacia Hidrográfica do rio Barigui, vizinha à área de estudo e que apresenta condições geológicas e geomorfológicas, em parte, similares, Bonacim (1996) obteve um escoamento superficial médio de $0,146 \mathrm{~m}^{3} \mathrm{~s}^{-1}$ para uma área de $33,617 \mathrm{~km}^{2}$, o que resultaria numa vazão específica média de $4,3 \mathrm{~L} \mathrm{~s}^{-1} \mathrm{~km}^{-2}$. Esta vazão menor talvez possa ser explicada em termos morfohidrológicos, pois a área em questão se situa sobre um platô sobrelevado em relação aos terrenos circundantes, de forma que perdas de água via subterrânea em direção às bacias hidrográficas vizinhas são normalmente esperadas.

Quanto à evapotranspiração potencial, Vestena e Kobyama (2007) estimaram para a bacia de estudo e para um período similar (1997 a 2000) a média anual de evapotranspiração de $1.141 \mathrm{~mm}$ com a equação de Penmam modificada, Nesse trabalho, utilizando a equação de Thornthwaite (período de 1998 a 2003) o valor médio anual foi de $892,37 \mathrm{~mm}$. Isso resulta em uma diferença de $249 \mathrm{~mm}$ de volume entre os dois resultados obtidos. Os valores de evapotranspiração para os anos de 1998, 1999 e 2000 são também menores que os encontrados em Vestena e Kobyama (2007), e que a média entre eles é também menor $(869,58 \mathrm{~mm})$ (Tabela 2). A diferença encontrada poderia ser devida ao diferentes métodos de calculo de evapotranspiração, pois em uma foi utilizada o de Penman modificada e, em outra, o de Thornthwaite.

O resultado médio da série de 19 anos (1974 a 1993) de evapotranspiração potencial, cálculo obtido pelo método de ThornthwaiteMather pelo Projeto Karst, foi de $766 \mathrm{~mm}$, próximo, porém abaixo do obtido nesse trabalho $(892,37 \mathrm{~mm})$. A diferença de resultados $(126 \mathrm{~mm})$ pode ser devido à utilização de anos diferentes efetuados para fazer o calculo. Entretanto, nota-se uma diferença de $285 \mathrm{~mm}$ entre o calculado por Vestena e Kobyama (2007) e o calculado pelo Projeto Karst (2007) (linha C, Tabela 3), sendo também elevada se comparada à evapotranspiração apresentada no Atlas Climático da Região Sul do Brasil (WREGE et al., 2011). A evapotranspiração potencial apresentada neste Atlas, entre 801 a $850 \mathrm{~mm}$ é o 
resultado médio de uma série climática de mais de 30 anos e apresenta valores próximos aos encontrados no presente trabalho (892 mm). Ainda para Wrege et al. (2011) os valores anuais da diferença entre precipitação e evapotranspiração estão entre 801 a 900 mm e para Vestena e Kobyama (2007) entre $369 \mathrm{~mm}$.

Estes valores são importantes pois influem diretamente no cálculo do balanço hídrico. Assim, compondo o balanço hídrico da bacia hidrográfica do carste utilizando os dados obtidos: média anual do total de precipitação de $1609 \mathrm{~mm}$ e média do total anual de evapotranspiração potencial de 892,37 mm (calculada pelo método de Thornthwaite) verifica-se um saldo de $717 \mathrm{~mm}$ que seria destinado a escoamento e infiltração. Pelo calculo de vazão (Tabela 1) verificou-se um escoamento (runoff) resultante de $743 \mathrm{~mm} / \mathrm{a}$, ou seja, com déficit de apenas $26 \mathrm{~mm}$. Essa diferença, somado à retirada de água dos poços de 369 mm, valores utilizados por Vestena e Kobyama (2007) para esse período totaliza $395 \mathrm{~mm}$.

Desta forma, durante o período considerado, pode ter ocorrido um fluxo de entrada de água subterrânea na bacia hidrográfica: seja externo, seja de água armazenada em litologias de menor permeabilidade no interior da própria bacia hidrográfica. O resultado do balanço hídrico da bacia hidrográfica, elaborado por Vestena e Kobyama (2007) para os anos de 1997 a 2000, considerando a pluviosidade, a evapotranspiração, a descarga e também a retirada de água dos poços levou os autores a concluírem que a bacia hidrográfica do rio Fervida recebeu uma recarga média anual de origem subterrânea de mais de $500 \mathrm{~mm} / \mathrm{a}$, valor superior ao encontrado nesse trabalho. O fato do calculo da evapotranspiração, elaborada pelos autores ter sido maior justificaria um valor mais alto encontrado para a recarga também.

Esta entrada de água subterrânea que deve estar ocorrendo na bacia é comum em sistemas cársticos, especialmente naqueles desenvolvidos em regiões tropicais e subtropicais úmidas, pois apresentam maior complexidade comparado a outros de regiões temperadas e semiáridas (FORD E WILLIAMS, 2007). Isso se deve ao desenvolvimento de espessos mantos "regolito argiloso" que, muitas vezes, se prolongam em maiores profundidades em zonas de 
falhas. No caso específico do carste na região do Açungui que abrange a bacia hidrográfica estudada tem-se a intercalação lateral de estratos de filitos e quartzitos que funcionam como aquicludes e, em dependência do nível de fraturamento, como aquitardes. A esse esquema se acrescentam os diques de diabásio que seguem a direção do Arco de Ponta Grossa, isso é NW - SE geralmente perpendiculares ao trend do embasamento do Açungui segundo NE-SW. Esses diques também funcionam como aquicludes e, eventualmente, aquitardes.

Observa-se assim que as águas subterrâneas que drenam o carste têm origens diversas implicam em diferentes tempos de residência e idades pretéritas maiores daquelas que seriam de esperar numa bacia hidrográfica ou num sistema cárstico desenvolvido unicamente sobre litologias carbonáticas com regolito reduzido.

Assim, apesar das diferenças de valores encontrados da evapotranspiração, o que resultou em valores também diferentes para 0 balanço hídrico, verifica-se que o mesmo, para bacia hidrográfica de Fervida, é negativo e que se não houvesse uma provável alimentação de água subterrânea vinda de locais adjacentes não haveria vazão suficiente na foz, comprometendo a segurança hídrica a jusante e em pontos a montante.

Deve-se considerar que a evapotranspiração calculada nesse trabalho foi a potencial, que é sempre maior que a real, mas como já mencionado anteriormente, há um intenso uso da irrigação na região o que faz com que evapotranspiração real deva ficar muito próxima da potencial.

\section{CONCLUSÃO}

$\mathrm{Na}$ bacia hidrográfica de Fervida, o balanço hídrico climatológico é deficitário, o que indica que existe fluxo de água subterrânea que recompõe a água perdida.

Apesar de ser uma bacia hidrográfica pequena comparada à extensão do carste, o comportamento hidrológico desta bacia hidrográfica pode se repetir em outras porções do carste e, assim, esse estudo serve como um alerta para que a segurança hídrica das áreas sobre esse aquífero possa ser considerada. 
O conhecimento do balanço hídrico da bacia é importante em função da demanda atual, mas também o futuro, considerando as alterações do uso da terra e mudanças climáticas que devem interferir no balanço hídrico devido às alterações na evapotranspiração e precipitação.

Para isso, o monitoramento da vazão das bacias hidrográficas deve ser constante, para que possa haver um uso racional e um planejamento futuro do conjunto das bacias hidrográficas da região.

\section{REFERÊNCIAS}

BARTH, F. T. Modelos para gerenciamento de recursos hídricos. São Paulo: Nobel, 1987

BOLLIMAN. H. A., GASPARIN, D.C., DUARTE, F. Restrição ambiental ou oportunidade para o desenvolvimento sustentável? Aquífero Carste na Região Metropolitana de Curitiba. Cad. Metropolitana, V.15, n.30, PP. 645-665. Dez 2013.

BONACIM, E. A. Dinâmica do sistema hidrogeológico cárstico na área de Tranqueira - Região Metropolitana de Curitiba. Curitiba, 1996. Dissertação. Mestrado em Geologia.

FALEIROS, F.; FERRARI, V. C.; COSTA V.S.; CAMPANHA, G.A.C.. Geoquímica e petrogênese de metabasitos do grupo Votuverava (Terreno Apiaí, Cinturão Ribeira Meridional): evidências de uma bacia retroarco calimiana. Geol. USP, Série. cient., São Paulo, v. 11, n. 2. Disponível em: http://ppegeo.igc.usp.br/scielo.php?script=sci_arttext\&pid=S1519-

874X2011000200008\&Ing=en\&nrm=iso >. Acesso: 17 março de 2015.

FORD, D.; WILLIAMS, P.D. Karst Hydrogeology and Geomorphology. New Jersey: Wiley, 2007. 576 p.

FRITZSONS, E.; MANTOVANI, L.E. Os Substratos Geológicos e os Coeficientes Morfométricos em Bacias Hidrográficas do Carste Dolomítico no Estado do Paraná (The Geological Substrates and Morphometric Coefficients in Dolomitic Karst in State of Paraná). Revista Brasileira de Geografia Física. 03 (2010) p. 181-189. Disponível em: http://ainfo.cnptia.embrapa.br/digital/bitstream/item/28887/1/115-709-1-PB.pdf.

Data da disponibilidade: 21/03/2016

FRITZSONS, E.; PARRON, L. MANTOVANI, L.E. Qualidade da água e o uso e cobertura da terra da bacia de Ribeirão da Onça, Colombo, Colombo : Embrapa Florestas, 2015. 26 p. - (Documentos / Embrapa Florestas, ISSN 1980-3958; 281). Disponível em: http://ainfo.cnptia.embrapa.br/digital/bitstream/item/131650/1/Doc.-281-

Qualidade-agua-Elenice.pdf. Acesso: 17/03/2015. 
HARTMANN, A., N.; GOLDSCHEIDER, T.; WAGENER, J.; LANGE; M. WEILER. Karst water resources in a changing world: Review of hydrological modeling approaches, Rev. Geophys., 52, 218-242. 2014, doi:10.1002/2013RG000443. Karst water resources in a changing world: Review of hydrological modeling approaches

HINDI, E. C.; ROSA FILHO, E. F. ; LUCENA, L.R.F. ; BITTENCOURT, A. L. ; MANTOVANI, L. E. ; XAVIER, J. M. ; NADAL, C. A. ; GIUSTI, D. A. . Características hidrogeológicas do aqüífero cárstico em Colombo (PR) e impactos ambientais resultantes da sua explotação. Anais do XII Congresso Brasileiro de Águas Subterrâneas. São Paulo: ABAS, 2002. v. 1. p. 50-61.

HINDI, E.C.; ROSA FILHO, E. F.; MANTOVANI, L.E.; LUCENA, L. R. F. Proposição de atributos para o aproveitamento de fontes naturais do aqüífero cárstico de Curitiba-PR, Brasil. Comunicações Geológicas (2013) 100, 1, 67$71 \mathrm{p}$.

INSTITUTO DAS ÁGUAS PARANÁ. 2015. Águas Paraná. Sistemas de informações hidrológicas. Aquífero Karst. Disponível em: http://www.sihweb.aguasparana.pr.gov.br/sihweb/gerarRelatorioResumoMedicaoDescarga.do ?action=imprimeRelatorioResumoMedicaoDescarga. Acesso: 17/03/2015.

JICA - JAPAN INTERNATIONAL COOPERATION AGENCY. The master plan study on the utilization of water resources in Paraná state in the Federative Republic of Brazil. Tokio :JICA. v. J: Soil and erosion Forest. 1995.

LISBOA, A. A.; BONACIM, E. A. Sistema aqüífero cárstico: reservatório elevado da Região Metropolitana de Curitiba. Revista SANARE. $n^{\circ} 4$. Curitiba, 1995. p. 26-30.

MAACK, R. Geografia física do Estado do Paraná. 2. ed. Rio de Janeiro : J. Olympio, 1981

PROJETO KARST (1998) INSTITUTO DE HIDROGEOLOGIA E GEOTERMIA Elisabethstrasse 16/II A. -8010 Graz / Austria. PROJETO CARSTE. Relatório conclusivo final. Disponível em

http://www.aguasparana.pr.gov.br/arquivos/File/rel final.pdf. Acesso: 07/01/2015.

ROSA FILHO, E; HINDI; E. C.; MANTOVANI, L. E. ; BITTENCOURT. A. V. L. Aquíferos do Estado do Paraná. Curitiba. Edição do autor, 2011. 200p.

TUCCI C.E.M., 2002. Gerenciamento da drenagem urbana. Revista Brasileira de Recursos Hídricos, 7(1):5-25. 2002. 
ASPECTOS HIDROLÓGICOS E HIDROGEOLÓGICOS DA BACIA DO RIO FERVIDA, AQUÍFERO CARSTE, COLOMBO, PARANÁ.

VESTENA, L. R.; KOBIYAMA, M. W. Balance in Carste: case study of the Ribeirão da Onça catchment in Colombo City, Paraná State - Brazil. Brazilian Archives of Biology and Technology, 2007, vol.50, n. 5, ISSN 1516-8913.

WREGE, M.S.; STEINMETZ, S.; REISSER Jr, C.; ALMEIDA, I.R. Atlas Climático da Região Sul do Brasil: Estados do Paraná, Santa Catarina e Rio Grande do Sul. Pelotas: Embrapa Clima Temperado; Colombo: Embrapa Florestas, 2011. $336 \mathrm{p}$. 